\title{
Physiological Attributes and Transcriptomics Analysis Reveal the Response Mechanism of Helictotrichon Virescens to Low-Temperature Stress
}

\section{Mingjun Cheng}

Institute qinghai-tibetan Plateau, Southwest Minzu University, Chengdu, 610041, China.

\section{Mingmin Zheng}

College of Chemistry and Life Sciences, Sichuan Provincial Key Laboratory for Development and Utilization of Characteristic Horticultural Biological Resources, Chengdu Normal University, C-hengdu, 611

\section{Kuoshu Cui}

Sichuan Agricultural Technology Extension Station, Chengdu, 610041, China.

\section{Ruizhen Zhang}

Sichuan Grass Industry Technology Research and Promotion Center, Chengdu, 610041, China.

\section{Tao Yang}

Maize Research Institute, Sichuan Agricultural University, Chengdu 611130, China.

\section{Xiaofeng Li}

Maize Research Institute, Sichuan Agricultural University, Chengdu 611130, China.

\section{Donghai Yan}

Sichuan Grass Industry Technology Research and Promotion Center, Chengdu, 610041, China.

\section{Mingjiu Yao}

Sichuan Grass Industry Technology Research and Promotion Center, Chengdu, 610041, China.

\section{Xuan Luo}

Institute of Agricultural Information and Rural Economy, Sichuan Academy of Agricultural Sciences, Chengdu, 610066, China.

\section{Muhammad Zafar lqbal}

Maize Research Institute, Sichuan Agricultural University, Chengdu 611130, China.

\section{Junjun Zheng}

Maize Research Institute, Sichuan Agricultural University, Chengdu 611130, China.

\section{Ruyu He ( $243535990 @ q q . c o m$ )}

Maize Research Institute, Sichuan Agricultural University, Chengdu 611130, China.

\section{Qingping Zhou}

Institute qinghai-tibetan Plateau, Southwest Minzu University, Chengdu, 610041, China.

\section{Research Article}


Keywords: Helictotrichon Virescens, Low-temperature stress, photosynthesis, Circadian rhythm, LHY, HY5 Posted Date: November 23rd, 2021

DOI: https://doi.org/10.21203/rs.3.rs-985479/v1

License: (c) (1) This work is licensed under a Creative Commons Attribution 4.0 International License. Read Full License 
2 Physiological attributes and Transcriptomics analysis reveal the

\section{response mechanism of Helictotrichon virescens to low-temperature}

\section{stress}

Mingjun Cheng ${ }^{1}{ }^{3^{\dagger}}$, Mingmin Zheng ${ }^{4^{\dagger}}$, Kuoshu $\mathrm{Cui}^{\mathrm{i}^{\dagger}}$, Ruizhen Zhang ${ }^{3}$, Tao Yang ${ }^{2}$, Xiaofeng $\mathrm{Li}^{2}$, Donghai $\mathrm{Yan}^{3}$, Mingjiu $\mathrm{Yao}^{3}$, Xuan $\mathrm{Luo}^{6}$, Muhammad Zafar Iqbal${ }^{2}$, Junjun Zheng ${ }^{2}$, Qingping Zhou $^{1 *}$, Ruyu He ${ }^{2 *}$

${ }^{1}$ Institute qinghai-tibetan Plateau, Southwest Minzu University, Chengdu, 610041, China.

${ }^{2}$ Maize Research Institute, Sichuan Agricultural University, Chengdu 611130, China.

${ }^{3}$ Sichuan Grass Industry Technology Research and Promotion Center, Chengdu, 610041, China.

${ }^{4}$ College of Chemistry and Life Sciences, Sichuan Provincial Key Laboratory for Development and Utilization of Characteristic Horticultural Biological Resources, Chengdu Normal University, Chengdu, 611130, China.

${ }^{5}$ Sichuan Agricultural Technology Extension Station, Chengdu, 610041, China.

${ }^{6}$ Institute of Agricultural Information and Rural Economy, Sichuan Academy of Agricultural Sciences, Chengdu, 610066, China.

${ }^{2}$ Maize Research Institute, Sichuan Agricultural University and ${ }^{1}$ Institute qinghai-tibetan Plateau, Southwest Minzu University are the common communication units for this study.

2*Ruyu He (243535990@qq.com) and Qingping Zhou ${ }^{1 *}$ (cmj013678@126.com) are the common correspondences.

\section{Abstract}

Background: Helictotrichon Virescens is a perennial herb mainly distributed in high altitude areas of $2000 \sim 4500 \mathrm{~m}$. It is widely cultivated in the Qinghai-Tibet Plateau of China, strongly resistant to cold, and an essential part of wild herbage in this region. However, the molecular mechanism of Helictotrichon virescens response to low-temperature stress is unclear, and the key regulating genes 
to specific biological processes are poorly known.

Results: It was used physiological and transcriptome analysis to study the cold stress response mechanism in Helictotrichon Virescens. Under low-temperature treatment at $0^{\circ} \mathrm{C}$, the leaves reduced chlorophyll content and light energy absorption through light antenna complex (LHCs). As the content of chlorophyll, a and b decreased, as evident were the photoprotection effects. Besides, circadian pathway-plant is crucial for the response to cold stress in Helictotrichon Virescens. Among them, DEG encoding LHY and HY5 showed strongly up-regulated expression during cold stress in

\section{Helictotrichon Virescens.}

Conclusions: This study provides an opportunity to fully understand the response process of Helictotrichon Virescens to low-temperature stress. It answers the pertinent questions in perennial herbaceous cold stress research, how leaves integrate light and low-temperature signals to regulate circadian rhythms in crops, and how leaf tissue reduces light absorption and enhances light protection through optical antenna complex (LHCs).

Keywords: Helictotrichon Virescens, Low-temperature stress, photosynthesis, Circadian rhythm, LHY, HY5

\section{Background}

Helictotrichon Bess is a perennial herb in the grass family comprising 100 species globally, mainly distributed in Asia, Europe, North America, and China. It's more than 20 species are an important part of wild forages in China, distributed in high altitude areas of $2000 \sim 4500 \mathrm{~m}$. Among them, Helictotrichon virescens, mainly distributed in high altitude areas like Tibet and Qinghai. Generally, It has strong cold tolerance, can survive winter successfully as low as $-25^{\circ} \mathrm{C}$, and has a life span of about ten years. It's artificial cultivation in the range of $2000-4000 \mathrm{~m}$ above sea level can produce higher seed and forage yield with an average annual seed yield of $0.948 \mathrm{t} / \mathrm{hm}^{2}$ per mu and hay yield of $7.74 \mathrm{t} / \mathrm{hm}^{2}$. It might be a first choice for improving natural grassland, the construction of artificial grassland, and the greening of the Tibetan Plateau's ecological environment. However, the molecular mechanism of the response to low-temperature stress is still unclear, and the key genes regulating related biological processes are poorly understood.

Low-temperature stress is a multi-genic process accompanied by physiological adjustments in the plant. Mechanisms of cold stress response in woody species are complicated than those in 
herbaceous ones [1]. Although phenotypic responses of herbs to photoperiod and low-temperature are well understood, little is known at the molecular level. Low temperatures can affect all aspects of plant physiology and metabolism, including photosynthesis, which is most affected by lowtemperatures stress [2]. Chlorophyll is the main pigment for photosynthesis. The first step of photosynthesis is the absorption of light energy by chlorophyll and the ionization of chlorophyll. Both chlorophyll A and B can absorb light energy, but only a few chlorophyll A in the excitation state can convert light energy into electrical energy [3]. In the first step of photosynthesis, antenna proteins capture and transfer light energy and convert it into chemical energy. Most of the energy is absorbed by the light antenna complex (LHCs). The light antenna complex includes most of the chlorophyll a, all of chlorophyll b and carotenoids, which can combine with PSI and PSII [4, 5]. Under low-temperature conditions, the photosynthesis rate reduction in plant leaves relates to lowtemperature damage to PSII reaction centers and chloroplasts. Photosystem II plays an essential role in plant response to low-temperature stress [6]. Previous research shows that plants' ability to absorb and utilize light energy significantly reduced under adverse conditions, leading to intensified photoinhibition [7].

Under low temperature and low light conditions, the photoinhibition degree of PSII and PSI intensifies, which is probably closely related to the accumulation of reactive oxygen species. After the occurrence of PSII photoinhibition, its activity is challenging to recover. Generally, it takes several days to recover completely. However, PSII photoinhibition can completely recover within a day or even a few hours. After photoinhibition, the PSI recovery slows down, which might be the main limiting factor of decreased photosynthesis rate at low temperatures. After photoinhibition, the PSII activity and light intensity significantly affect PSI recovery in vivo [7]. Therefore, it is suggested that photoinhibition is a temporary or persistent form of light protection and plays an essential role during cold stress. Plants synchronize the endogenous rhythm (physiology and metabolism) with environmental rhythm by integrating changes with environmental conditions (light and temperature) during the day-night cycle [8]. Many genes have been reported to respond to light and show regular variations in the day-light dark cycle, like members of the circadian rhythm. For example, E3 ubiquitin-protein ligase COP1 post-transcriptionally affects HY5 expression [9], HY5 is a transcription factor of the basic leucine zipper (bZIP) family and multiple downstream photoreceptors $[10,11]$. These genes are transcriptionally affected by light and low temperature and 
relate to the complete development of cold tolerance in Arabidopsis [12]. LHY is an MYB-related transcription factor categorized as a morning gene of the circadian clock [13]. Studies have also shown that the biological clock is the gateway to induce genes related to cold, such as C-repeat Binding Factor (CBF) [14]. CBF transcription factor plays a key role in low-temperature stress in plants and one of the essential transcription factors that can interact with DRE/CRT cis to regulate gene expression induced by multiple adverse conditions. Proteins encoded by COR (Cold Regulated) genes have strong hydrophilicity and thermal stability and can play an essential role in preventing cell dehydration damage caused by low-temperature stress. The overexpression of CBF genes in Arabidopsis thaliana [15] or transfer of CBF homologous genes into other plant species could enhance the low-temperature stress tolerance.

Currently, it was studied the response mechanism of perennial herbaceous plants to cold stress using Helictotrichon Virescens as research material. The unique biological characteristics of Helictotrichon Virescens offer an opportunity to explore the role of light protection and circadian rhythm during cold stress and lay a theoretical foundation for further understanding of the response mechanism to cold stress in perennial crop.

\section{Results}

Morphological and physiological changes in Helictotrichon Virescens under low-temperature stress

Under low-temperature stress, Helictotrichon Virescens showed leaf wilting, leaf tip shrinkage, water loss (Fig.1), and the gradual decline of chlorophyll content by extending stress time (Fig.2-a and b). After 12 hours of low-temperature stress, the contents of chlorophyll b reduced significantly, but the change in chlorophyll a was non-significant. After $36 \mathrm{~h}$ and $60 \mathrm{~h}$ of low-temperature stress, the contents of chlorophyll a and $\mathrm{b}$ in the treatment group were significantly lower than those in the control group. The results indicated that chlorophyll content changed significantly after lowtemperature stress, and chlorophyll b decreased more rapidly in response to low-temperature stress. Also, the relative conductivity of leaves increased after low-temperature stress (Fig2-c). After 12 hours of low-temperature stress, the relative conductivity of leaves in the treatment group was significantly higher (1.15 times) than that of the control group. After $60 \mathrm{~h}$ of low-temperature stress, the relative electrical conductivity of leaves in the treatment group increased up to 2.90 times that 
of the control group. The results indicated the stability and tolerance of the leaf cell membrane affected by low-temperature stress. Under low-temperature stress, the accumulation of proline (Pro) could reduce the freezing point of cell solute and improve the osmotic potential, thus stabilizing the cell membrane system to prevent freezing dehydration decreased solute exudation. After $12 \mathrm{~h}$ of low-temperature stress, the Pro content of leaves in the treatment and control groups showed a highly significant difference (Fig.2-d). The Pro contents in the treatment group were 2.16 times higher than the control group. By extending stress time, the Pro content did not change significantly. After $12 \mathrm{~h}$ of low-temperature stress, the increase of Pro content in the plant saturated. ROS content gradually increased by extending stress time (Fig.2-e) with significant or highly significant differences between treatment and the control groups. Simultaneously, the POD, SOD, and CAT activities significantly enhanced (Fig.2-f, g, and h), which were conducive to eliminate ROS and reduced ROS damage in plants.

In conclusion, the low-temperature stress significantly changed the morphology, physiological and cell solutes of Helictotrichon Virescens, damaged leaf cells tolerance and stability and suppressed its growth. Meanwhile, low-temperature produced some of the osmotic regulation hormones to alleviate low-temperature damage, but specific responses and regulation mechanisms are still unclear. Therefore, it is necessary to conduct further research.

\section{Sequence assembly and splicing}

High Illumina HiSeq ${ }^{\mathrm{TM}}$ flux sequencing platform was used for transcriptome sequencing of Helictotrichon Virescens leaves after low-temperature stress of 18 samples and obtained a total of $24000000 \mathrm{bp}$ raw data. After assembling and removing the redundancy, the high-quality sequence data with a length of 22730, 000bp was obtained. Each sample Clean reads exceeded 6.5 G, indicating a high sequencing depth. The base error rate of the sequenced column for each sample was $0.02 \%-0.03 \%$, Q20 and Q30 were above $98.00 \%$ and $94.00 \%$, respectively, and GC contents were above $50.21 \%-55.21 \%$ (Table. S1).

Clean reads have 396,649 transcriptional sequences obtained through Trinity splintering used as reference sequences for subsequent analysis. Table.S2 shows the statistical results of reference alignment. The comparison efficiency between Clean reads of 18 samples and the reference genome was higher, all above $70 \%$, meeting subsequent analysis needs. The transcriptome sequences were 


\begin{tabular}{ccc}
\multicolumn{3}{c}{ Table 1 Statistics of gene annotation } \\
\hline Database & Number of Unigenes & Percentage/\% \\
\hline Annotated in NR & 60901 & 45.92 \\
Annotated in NT & 57147 & 43.09 \\
Annotated in KO & 18765 & 14.15 \\
Annotated in SwissProt & 39512 & 29.79 \\
Annotated in PFAM & 45144 & 34.04 \\
Annotated in GO & 45140 & 34.03 \\
Annotated in KOG & 10100 & 7.61 \\
Annotated in all Databases & 7449 & 5.61 \\
Annotated in at least one Database & 132612 & 100 \\
Total Unigenes & 132612 & 100
\end{tabular}

assembled into 112,775 Unigene through Corset hierarchical clustering for subsequent correlation analysis. The Transcripts of N50 and N90 of Unigene were 1579, 549, 1426, and 452, respectively; larger N50 and N90 showed the overlapping of transcripts (Table. S3 and S4).

\section{Gene functional annotation}

We annotated the obtained unigenes for gene functions using seven major databases $(\mathrm{Nr}, \mathrm{Nt}$, Pfam, KOG, Swiss-Prot, KO, GO) (Table 1). There were 57,147 Unigenes (43.09\%) in Nt database, 60,901 Unigenes (45.92\%) in $\mathrm{Nr}$ database, 45,144 Unigenes (34.04\%) in PFAM database, 45,140 Unigenes (34.03\%) in GO database, and 39,512 Unigenes (29.79\%) in Swiss-Prot database. There were 18,765 Unigenes (14.15\%) in KO database and 10,100 Unigenes (7.61\%) in KOG database. It is worth noting that NCBI nucleic acid sequence database $(\mathrm{Nt})$ and NCBI protein sequence database $(\mathrm{Nr})$ have higher annotation rates.

Table 1 Statistics of gene annotation

By comparing the results of the comments with the NR library, the homologous gene similarity rate with the Helictotrichon Virescens was the highest (29.4\%); followed by Brachypodium distachyon (18.4\%), Hordeum vulgare (10.4\%), Triticum aestivum (7.0\%), Triticum urartu (6.7\%) and other species (28.1\%) (Fig. 3-a). In conclusion, Unigene's highest distribution rate in the NR database, indicating that genomes of the two species were the most similar. However, a few of them 
were in Brachypodium distachyon, Hordeum vulgare, and Triticum aestivum, indicating the evolutionary overlap between the Helictotrichon Virescens and the above species. In the sequence of Helictotrichon Virescens, $10.6 \%$ of genes have a sequence similarity of $95-100 \%, 36.1 \%$ genes have a sequence similarity of $80-95 \%, 39.1 \%$ genes have a sequence similarity of $60-80 \%$, and $14 \%$ genes have a sequence similarity of 40-60\% (Fig. 3-b).

\section{Analysis of differential gene expression}

Based on expression profile, the gene expression level was divided into 6 grades (Fig. 4-a). $0 \sim 0.1,0.1 \sim 0.3,0.3 \sim 3.57,3.57 \sim 15,15 \sim 60$, and $>60$ represented very low, low, moderate, high, and ultra-high and an overexpressed gene expression levels, respectively. By increasing the expression level, its proportion gradually decreased. Compared with the control group, the proportion of extremely low, low, and ultra-high expressed genes was higher in the treatment group. In contrast, the balance of moderate, high, and overexpressed genes were more insufficient. Based on correlation analysis on gene expression values (FPKM) of all samples (Fig. 4-b), the expression patterns within the group were highly similar, but differences between were greater. DEG-seq was used to screen the differentially expressed genes between the low-temperature treatment and control groups (fold change $>2$, FDR $<0.01$ ). Low-temperature treatment of $12 \mathrm{~h}$ differentially expressed 18184 genes (Fig. 4-c); among them, 10047 up-regulated and 8137 down-regulated. At $36 \mathrm{~h}$ of low-temperature treatment (Fig. 4-d), a total of 32,753 genes expressed differentially; among them, 16,251 upregulated and 16,502 down-regulated. At $60 \mathrm{~h}$ of low-temperature treatment (Fig 4-e), a total of 28092 genes were differentially expressed, of which up-regulated 14,912 genes and down-regulated 13,180 genes. Results indicated that the gene expression in leaves of Helictotrichon Virescens changed significantly under low-temperature stress.

\section{GO Enrichment of DEGs}

To better explain the biological function of DEGs, it was performed GO enrichment analysis on the differentially expressed genes after $12 \mathrm{~h}, 36 \mathrm{~h}$, and $60 \mathrm{~h}$ treatment, which showed that 18184 DEGs enriched into 2675 biological processes; among them, 28 biological processes enriched significantly after $12 \mathrm{~h}$ treatment of low temperature. Of which, 10 Cellular components significantly enriched a total of 1231 molecular functions and 27 enriched significantly. After $36 \mathrm{~h}$ treatment, 
32753 DEGs enriched 2920 Biological processes; among them, 62 significantly enriched. Among 657 Cellular components, four enriched significantly. Among 1394 enriched molecular functions, 15 enriched significantly. After 60h treatment, 28092 DEGs enriched 2846 biological processes, of which 45 enriched significantly. In the process of enrichment of 645 Cellular components, 9 Cellular components enriched significantly. Among.1344 enriched molecular functions, ten were significantly enriched.

It was analyzed the first 20 biological processes with significantly enriched genes after $12 \mathrm{~h}$, $36 \mathrm{~h}$, and $60 \mathrm{~h}$ treatment. The results showed that 11 Biological processes with differentially expressed genes were co-enriched and related to carbohydrate catabolism and metabolism (Fig. S1). Carbohydrate and sugar metabolism belong to respiration [16], which along with photosynthesis, are important for carbohydrate metabolism and sensitive to temperature [17]. The low-temperature stress can reduce the accumulation of carbohydrates in plants and affects cell osmotics or cryoprotectants. Therefore, it was hypothesized that photosynthesis and respiration determine carbohydrate metabolism, which affects the improvement of cold tolerance in plants.

Also, differentially expressed genes are enriched in specific biological processes, such as protein phosphorylation, protein denaturation, oxidative stress, peroxidase reactions, water response, and oxygen-containing reactions.

\section{KEGG Enrichment of DEGs}

After $12 \mathrm{~h}, 36 \mathrm{~h}$ and $60 \mathrm{~h}$ of low-temperature treatment, a total of 9,416 DEGs enriched into 118 metabolic pathways (Table. S5) (Fig. 4-f). Among them, 13 pathways were significantly enriched, namely; photosynthesis - antenna proteins (67 DEGs), Circadian rhythm (35 DEGs), starch and sucrose metabolism (104 DEGs), plant-pathogen interaction (92 DEGs), galactose metabolism (39 DEGs), Phenyl propanoid biosynthesis (86 DEGs), Plant hormone signal transduction (71 DEGs), Flavonoid biosynthesis (19 DEGs), photosynthesis (29 DEGs), Alpha-Linolenic acid Metabolism (28 DEGs), Amino sugar and nucleotide sugar metabolism (51 DEGs), Carbon fixation in photosynthetic organisms (41 DEGs) and Diterpenoid biosynthesis (11 DEGs).

KEGG analysis of DEGs at $12 \mathrm{~h}, 36 \mathrm{~h}$, and $60 \mathrm{~h}$ under low-temperature stress showed that they enriched 119, 120 and 120 metabolic pathways, respectively (Table. S6, S7 and S8). Among them, 17, 15 and 11 pathways enriched significantly, and nine pathways were co-enriched, including 
Photosynthesis - antenna proteins、Circadian rhythm - plant、Plant hormone signal transduction、

Photosynthesis 、 Flavonoid biosynthesis 、 Pentose phosphate pathway 、 Phenylpropanoid biosynthesis、 Fructose and mannose metabolism, and Plant-pathogen interaction (Fig. S2). In this study, three significant enriched KEGG pathways, namely: Photosynthesis - antenna proteins, Circadian rhythm - plant and Photosynthesis were analyzed in-depth; the results showed that 73, 74 and 70 DEGs annotated into the photosynthesis -antenna proteins pathway at $12 \mathrm{~h}, 36 \mathrm{~h}$ and $60 \mathrm{~h}$, respectively, Among them,Lhca1、Lhca2、Lhca3、Lhca5、Lhcb1、Lhcb3、Lhcb4、Lhcb5、Lhcb6 and $L h c b 7$ were up-regulated after low-temperature treatment (Fig.5-b). Low-temperature treatment up-regulated the expression of genes encoding PSI subunit ( $p s a A 、 p s a D$ and $p s a E$ ) and PSII subunit ( $p s b A 、 p s b C$ and $p s b O)$ in the photosynthetic pathway (Fig.5-c). Also, low-temperature treatment up-regulated genes encoding ATPase subunits ( $A T P F 1 B 、 A T P F 1 A 、 A T P F 1 G 、 A T P F 1 D$ and $A T P F 0 B)$ (Fig.5-c). In the Circadian rhythm -- plant pathway, DEGs encode E3 ubiquitin-protein ligase (V),

transcription factor HY5, MYB-associated transcription factor (LHY), PHYB and PIF3, respectively. Among them, the expression of COP1 and HY5 up-regulated between low-temperature treatments (Fig. 5-d). LHY is an MYB-related transcription factor and a morning gene belonging to the biological clock [13]. In this study, the initial expression level of LHY was significantly different between the control and the low-temperature treatment, and the low-temperature treatment upregulated its expression (Fig.5-d). The transcription factors interacting with photosensitive pigment B (PHYB) and photosensitive pigment (PIF3) are classified as "Morning genes" together with LHY, whose expression enhances the expression of PHYB and PIF3 in the biological clock. Thus, these DEGs' expression levels in this study suggest that low temperatures themselves disrupt the circadian rhythm of Helictotrichon virescens.

\section{Effects of low temperature stress on expression of transcription factors in Helictotrichon} Virescens

In order to investigate the effect of low temperature stress on transcription factor expression of Helictotrichon virescens, low temperature and normal temperature treatments were carried out, and the differential expression of transcription factor genes (TFs) was analyzed after transcriptome sequencing. The results showed that 2323 differentially expressed transcription factor genes were obtained under low temperature stress. All transcription factor genes obtained were family classified, 
and the results showed (Fig. 6) that all transcription factor genes of Helictotrichon virescens were classified into 84 transcription factor families, the top 10 transcription factor families were AP2/ERF, FAR1, TRAF, C2H2, bHLH, B3, bZIP/GRAS, C3H, AUX/IAA and GARP-G2-like.

The expression multiples of transcription factor genes were analyzed, and the transcription factor genes differentially expressed under low temperature stress were classified by Ration (the ratio of FPKM value under low temperature stress to FPKM value under normal temperature stress) as the classification index, the results showed (Fig. 7) that the distribution of multiple changes of transcription factor genes under different time treatments was basically the same, with the most transcription factor genes with expression multiple less than 10 times, the number of transcription factor genes contained after $12 \mathrm{~h}, 36 \mathrm{~h}$ and $60 \mathrm{~h}$ treatment was 2242, 2246 and 2264, respectively, Among them, the number of transcription factor genes whose expression multiple was less than 10 times was the most (2264) after 60h of low temperature treatment; After 12h of low temperature treatment, the number of transcription factor genes with expression multiple of more than 100 times was the highest (19); After 36h of low temperature treatment, the number of transcription factors with expression multiples between 50-100 times was the highest (12). These results indicate that under low temperature stress, most transcription factor genes have little changes and have little influence on gene expression regulation. Only a few transcription factor genes have undergone drastic changes, which have a great influence on gene expression regulation.

The transcription factors with large differential multiples were analyzed, and the transcription factor genes with the top 15 differential expression multiples were selected for analysis under different treatment times, the results showed (Table 2, 3 and 4) that all transcription factors were up-regulated after $12 \mathrm{~h}$ of low temperature treatment, Among which, 6 transcription factors were AP2/ERF family, 2 were $\mathrm{C} 2 \mathrm{H} 2$ family, and bZIP family had the highest differential expression rate; After 36h of low temperature treatment, all transcription factors were up-regulated, among which 6 transcription factors were AP2/ERF family, 3 were $\mathrm{C} 2 \mathrm{H} 2$ family, and bZIP family had the highest differential expression rate; After $60 \mathrm{~h}$ of low temperature treatment, all transcription factors were up-regulated, Among them, 5 transcription factors were AP2/ERF family, 2 were $\mathrm{C} 2 \mathrm{H} 2$ family and 2 were MYB family. As can be seen from the above transcription factor families with large multiple differences, there are different types of transcription factor families with large multiple differences 

resistance, mainly concentrated in the AP2/ERF, MYB, bZIP and C2H2 families.

Table 2 Transcription factors with large difference multiple under low temperature stress (after $12 \mathrm{~h}$ treatment)

\begin{tabular}{ccc}
\hline Gene ID & Transcription factor family & Fold change \\
\hline Cluster-37118.4686-2R & bZIP & 88341.3333 \\
Cluster-37118.77201-0R & Others & 6598.2979 \\
Cluster-37118.4799-1R & C2H2 & 6392.1111 \\
Cluster-37118.77199-2R & Others & 3195.1250 \\
Cluster-37118.77320-1R & AP2/ERF->AP2/ERF-ERF & 2227.8444 \\
Cluster-37118.11780-2F & AP2/ERF->AP2/ERF-ERF & 1249.2024 \\
Cluster-37118.77321-0R & AP2/ERF->AP2/ERF-ERF & 1183.3407 \\
Cluster-37118.72253-2F & MYB->MYB-related & 538.0743 \\
Cluster-37118.3964-1R & AP2/ERF->AP2/ERF-ERF & 306.3556 \\
Cluster-37118.4863-0R & C2H2 & 253.1799 \\
Cluster-37118.56181-2R & Others & 247.4655 \\
Cluster-37118.28893-2R & Others & 200.5954 \\
Cluster-37118.54292-1F & DBB & 186.1898 \\
Cluster-37118.1583-2F & AP2/ERF->AP2/ERF-ERF & 182.6875 \\
Cluster-37118.77341-1F & AP2/ERF->AP2/ERF-ERF & 149.0179 \\
\hline
\end{tabular}

Table 3 Transcription factors with large difference multiple under low temperature stress (after 36h treatment)

\begin{tabular}{ccc}
\hline Gene ID & Transcription factor family & Fold change \\
\hline Cluster-37118.4686-2R & bZIP & 3500.3750 \\
Cluster-37118.4799-1R & C2H2 & 1093.4699 \\
Cluster-37118.3361-0F & bHLH & 831.0000 \\
Cluster-37118.4866-1F & C2H2 & 829.4348 \\
Cluster-37118.77199-2R & Others & 758.7011 \\
Cluster-37118.77201-0R & Others & 678.4683 \\
Cluster-37118.4864-2F & C2H2 & 295.2523 \\
Cluster-37118.3966-0R & AP2/ERF->AP2/ERF-ERF & 189.6154 \\
Cluster-37118.72253-2F & MYB->MYB-related & 185.3746 \\
Cluster-37118.1583-2F & AP2/ERF->AP2/ERF-ERF & 123.5714 \\
Cluster-37118.77320-1R & AP2/ERF->AP2/ERF-ERF & 110.0485 \\
Cluster-37118.28893-2R & Others & 104.2324 \\
Cluster-37118.3964-1R & AP2/ERF->AP2/ERF-ERF & 103.9017 \\
Cluster-37118.11780-2F & AP2/ERF->AP2/ERF-ERF & 99.9809 \\
Cluster-37118.77321-0R & AP2/ERF->AP2/ERF-ERF & 92.8544 \\
\hline
\end{tabular}

Table 4 Transcription factors with large difference multiple under low temperature stress (after $60 \mathrm{~h}$ treatment) 


\begin{tabular}{ccc}
\hline Gene ID & Transcription factor family & Fold change \\
\hline Cluster-37118.77201-0R & Others & 3350.0000 \\
Cluster-37118.77199-2R & Others & 662.9641 \\
Cluster-37118.4686-2R & bZIP & 385.6364 \\
Cluster-37118.4799-1R & C2H2 & 229.1000 \\
Cluster-37118.3964-1R & AP2/ERF->AP2/ERF-ERF & 161.6961 \\
Cluster-37118.41131-0R & Others & 160.0000 \\
Cluster-37118.72253-2F & MYB->MYB-related & 154.8268 \\
Cluster-37118.3966-0R & AP2/ERF->AP2/ERF-ERF & 152.0417 \\
Cluster-37118.4550-1F & MYB->MYB & 152.0000 \\
Cluster-37118.77390-0R & C2H2 & 103.2381 \\
Cluster-37118.28893-2R & Others & 98.7612 \\
Cluster-37118.78083-0F & AP2/ERF->AP2/ERF-ERF & 97.6000 \\
Cluster-37118.77321-0R & AP2/ERF->AP2/ERF-ERF & 87.8077 \\
Cluster-2448.0-0R & AP2/ERF->AP2/ERF-ERF & 80.0000 \\
Cluster-37118.56181-2R & Others & 57.3731 \\
\hline
\end{tabular}

\section{RT-PCR verified the results of transcriptome sequencing}

To verify RNA- seq data's accuracy, we randomly selected 6 DEGs involved in circadian rhythm, Plant hormone signal transduction, Photosynthesis and Photosynthetic - antenna protein pathway for RT-PCR. The up-regulated or down-regulated DEGs in qPCR were consistent with RNA-seq analysis results (Fig. 8).

\section{Discussion}

As an advantage of natural grassland improvement and ecological environment greening in the Qinghai-Tibet Plateau area from Helictotrichon Virescens

In this study, through NR database comparison, it was found that the species with the highest homologous gene similarity with the Helictotrichon Virescens was Brachypodium distachyon, followed by Hordeum vulgare and Triticum aestivum, and there was a partial overlap between the Helictotrichon Virescens and the above species in evolution. Brachypodium distachyon is an annual herb that originated in western Asia and is highly adaptable. Hordeum vulgare and Triticum aestivum are annual plants, which are found at high elevations. In the course of evolution, the unique biological characteristics of Oatmeal have formed. Its perenniality attributes and strong cold tolerance provide a guarantee for the improvement of natural grassland and the greening of the ecological environment in the Qinghai-Tibet Plateau. 
Helictotrichon Virescens reduces ROS damage by increasing Antioxidant enzyme activity during cold stress

Reactive oxygen species (ROS) are the natural by-product of normal oxygen metabolism and plays essential roles in cell signal transduction and homeostasis. Plants under adverse environmental conditions produced ROS, which can damage cell structures and cause oxidative stress. Simultaneously, plants have ROS scavenging mechanisms, including enzymatic and non-enzymatic systems in which antioxidant enzymes are important ROS scavengers. In this study, ROS content was gradually increased by extending treatment time (Fig. 2-e). Specifically, after $12 \mathrm{~h}$ and $36 \mathrm{~h}$ of low-temperature stress, ROS contents were significantly different between treatment and control groups. After $60 \mathrm{~h}$ of low-temperature stress, ROS content was significantly different between the treatment and control groups.

Meanwhile, low-temperature stress up-regulated the genes regulating oxidative stress response (Cluster37118.30992) (Fig. 5-a). Besides, by extending treatment time, antioxidant enzymes such as POD, SOD and CAT increased gradually. Specifically, after $12 \mathrm{~h}$ of low-temperature stress, the contents of POD, SOD and CAT were significantly different between the treatment and control groups. After $36 \mathrm{~h}$ and $60 \mathrm{~h}$ of low-temperature stress, POD, SOD, and CAT contents were significantly different between the treatment and control groups. Simultaneously, under lowtemperature stress, the gene Cluster37118.16911 regulated Peroxidase activity (POD), and the gene Cluster37118.62042 up-regulated the response to oxygen-containing compound (SOD, etc.), which was consistent with the results of physiological experiments (Fig. 2-f, g and h). These results indicated that POD, SOD and CAT were beneficial to ROS clearance and reduced ROS damage in plants during low temperature and cold stress.

Also, autophagy is another important process of the life cycle, usually triggered by starvation and ROS and promoted by sucrose non-ferment-associated kinase 1 (SnRK1) or autophagyassociated (ATG) signaling [18]. Autophagy is a conservative cellular process that circulates cytoplasmic components. It is maintained at the basic level under normal conditions and activated under stress conditions such as carbon starvation, oxidative stress and sugar overload in eukaryotes $[18,19]$. Autophagy is crucial for nutrient cycling in plant vegetative organs [20]. Borja BeldaPalazon [21] showed that under normal growth conditions, SnRK2 and PP2C formed complexes 
with SnRK1, which inhibited the activity of SnRK1, and the growth promotion factor TOR could function normally and promote growth. Under adverse conditions, plants produce ABA, and ABA promotes the binding of PYR/PYL to PP2C and the cleavage of the SNRK2-PP2C-SNRK1 complex, which activates SnRK1, inhibits TOR activity, and inhibits growth. Since carotenoids are precursors to ABA, they can affect ABA content [22]. In this study, low-temperature stress inhibited the synthesis of carotenoid content. With the prolongation of treatment time, carotenoids' content decreased gradually, which further affected ABA content in plants.

\section{The content of chlorophyll a and b decreased during cold stress, which might be related to}

\section{light protection}

In this study, leaf tissues of Helictotrichon Virescens attempted to reduce the absorption of light energy through optical antenna complexes (LHCs) during low-temperature stress. Chlorophyll a and b contents in the treatment and control groups showed no significant difference after being treated with low-temperature stress for $12 \mathrm{~h}$ (Fig. 2-a and b). After $36 \mathrm{~h}$ and $60 \mathrm{~h}$ of low-temperature treatment, the content of chlorophyll a and b was significantly different between the treatment and control groups. Besides, the genes encoding light-capture protein complexes, such as Lhcal 、Lhca2、 Lhca3、Lhca5、Lhcb1、Lhcb3、Lhcb4、Lhcb5、Lhcb6 and Lhcb7, were up-regulated after cold treatment. Cold treatment up-regulated the genes encoding PSI subunit ( $p s a A 、 p s a D$ and $p s a E$ ) and the genes encoding PSII subunit ( $p s b A 、 p s b C$ and $p s b O)$ (Fig. 5-b). These results indicated that leaves tried to reduce light absorption by reducing chlorophyll content during low-temperature treatment. As much as chlorophyll a and b content decreased, the light protection effect became noticeable. Therefore, it is proposed that photoinhibition is a temporary or persistent form of photoprotection, which plays an important role in the low-temperature stress tolerance in Helictotrichon Virescens.

\section{Circadian rhythm plays an important role during cold stress of Helictotrichon Virescens}

Studies have shown that the circadian clock is the gateway to induce genes related to cold stress. LHY belongs to the morning gene of the circadian clock; in perennial woody plants, winter conditions (short photoperiod and low temperature) disrupt the expression of LHY in chestnut trees, leading to high expression in winter [23]. In this study, DEG encoding LHY showed a strong up- 
regulation during the cold treatment of Helictotrichon Virescens (Fig. 5-d). HY5 regulates many genes through transcription, making it the central hub of the transcription network [24]. It induces $10 \%$ of the cold-induced genes in Arabidopsis thaliana as a positive regulator of cold domestication [12]. In this study, DEGs encoding HY5 showed a strong up-regulation during the cold treatment of Helictotrichon Virescens (Fig. 5-d). Therefore, it is speculated that the circadian rhythm pathway is important to the low-temperature response of Helictotrichon Virescens.

Transcriptional regulation of transcription factors is a key part of the response of Helictotrichon Virescens to low temperature stress

Transcriptional regulation of transcription factors is a key part of plant response to low temperature stress. At present, transcription factors involved in low temperature signal response include P2/ERF, NAC, WRKY, MYB, bZIP and ZFPs [25]. Each transcription factor basically contains four independent structural domains, namely DNA binding domain, transcriptional functional domain, nuclear localization signal and oligomerization site [26], the main function of transcription factor in expression regulation network is determined by its transcriptional functional domain. The results of this study showed that all transcription factor genes of Helictotrichon Virescens were classified into 84 transcription factor families (Fig. 6), the top 10 transcription factor families were AP2/ERF, FAR1, TRAF, C2H2, bHLH, B3, bZIP/GRAS, C3H, AUX/IAA and GARP-G2-like, most of the transcription factor genes belong to the transcription factor family related to resistance. According to the analysis results of multiple differences of transcription factor genes in this study (Fig. 7), transcription factor families with greater differential expression also contain resistance related transcription factor families such as AP2-ERF and bZIP under different time treatments. The existence of these same types of resistance related transcription factor genes suggests that there are some common response mechanisms in Helictotrichon Virescens under low temperature stress.

Plant cold resistance is a quantitative trait controlled by multiple genes, and there are great differences among varieties with different cold resistance, and the types and expression amounts of transcription factors differentially expressed under low temperature stress are different. Changes in the expression levels of specific transcription factors can greatly affect the ability of plants to adapt to adversity [27]. The results of this study showed that although the types and expression patterns 
of transcription factors related to cold tolerance of Helictotrichon Virescens at different time treatments generally had the same trend, there were still some differences, and the transcription factors under different time treatments showed a certain time specificity in their transcription levels. In terms of expression levels of transcription factors (Table 2, 3 and 4), the transcription factors with large differences were mainly distributed in bZIP, C2H2 and AP2/ERF families after $12 \mathrm{~h}$ of low temperature treatment; After 36h of low temperature treatment, transcription factors with large multiple differences were mainly distributed in bZIP, $\mathrm{C} 2 \mathrm{H} 2$ and bHLH families; After 60h of low temperature treatment, transcription factors with large multiple differences were mainly distributed in bZIP, $\mathrm{C} 2 \mathrm{H} 2$ and some unknown gene families. This unique transcription factor family and unique transfactor genes with large multiple differences are likely to be an important reason for the enhancement of cold tolerance in Helictotrichon Virescens under different time treatments, and it is worthy of further study to clarify the transcriptional regulation mechanism of Helictotrichon Virescens under low temperature stress.

\section{Conclusions}

In order to elucidate the mechanism of response to cold stress of Helictotrichon Virescens, this study was based on a combination of physiological experiments and transcriptomic sequencing. The research results show that: at low temperature, ROS content accumulation was the same as POD, SOD and CAT activity, the gene that regulates POD activity (Cluster37118.16911) and the gene that regulates ROS (Cluster37118.62042) may be involved in ROS elimination during low-temperature treatment. During the cold treatment of Helictotrichon Virescens, the leaf tissue attempts to reduce light energy absorption through the optical antenna complex (LHCs). In contrast, the leaf attempts to reduce the absorption of light by reducing the chlorophyll content. Therefore, it is proposed that photoinhibition is a temporary or persistent form of light protection and plays an important role during cold treatment. Finally, circadian pathways are essential in response to cold stress in Helictotrichon Virescens. Among them, the DEG of LHY showed strong up-regulation under cold stress. DEGs encoding HY5 showed strong up-regulation under cold stress.

This study provides an opportunity to fully understand the mechanism of response to cold stress of Helictotrichon Virescens. It raises questions in perennial herbaceous cold stress research, such as how leaves integrate light and low-temperature signals to regulate the circadian rhythms of crops 
and how leaf tissue reduces light absorption and enhances light protection through optical antenna complex (LHCs).

\section{Methods}

\section{Plant Materials and Growth Conditions}

In 1999 Sichuan Grassland Work Station, Grassland Station of Ganzi Prefecture, Sichuan Province and Sichuan Jinzong Liaoyuan Seed Industry Technology Co. Ltd got a few seeds of Helictotrichon Virescens from Ganzi Prefecture forage germplasm resource collection of Sichuan Province. During propagation, plants turned green early, showed better growth and forage quality (Fig.9). After several years of selection and domesticated, new varieties were bred, and in 2015, Sixth China grass variety Approval Committee approved it as a wild cultivar. Variety applicants are Guangwu He, Ruizheng Zhang, Tao Ma, Dengkai Liu and Mingjiu Yao, the variety examination unit is China Grass Variety Examination Committee, and the variety registration number is 493. Helictotrichon Virescens is the first and only forage variety of Helictotrichon Virescens approved by the state in China. Currently, the seeds are stored in a cryogenic freezer at the Sichuan Grass Industry Technology Research and Promotion Center.

This study uses Helictotrichon Virescens as experimental material. Seeds were sown in flowerpots $(21 \mathrm{~cm} \times 16 \mathrm{~cm})$ containing matrix (peat, pine needles, and yellow clay, volume 3:1:1). When the first leaves expanded fully, we selected eight strains of each material with three replications and transferred them into 1/2 Hogland nutrient solution, then collected the samples from 5 weeks old seedlings for the relevant experiment. The collected leaf tissues were immediately frozen in liquid nitrogen on the sampling day and stored at $-80^{\circ} \mathrm{C}$.

\section{Low temperature and cold stress treatment on Helictotrichon. Virescens plants}

After separating five weeks old seedlings into control and treatment groups, it was treated the seedlings with low temperatures stress in a constant temperature and light in an incubator (MODEL: MLR-352H-PC) of the Cell Genetics Laboratory of Maize Research Institute of Sichuan Agricultural University by following complete block design (CBD). The low-temperature and control groups constantly remained at $0^{\circ} \mathrm{C}$ and $25^{\circ} \mathrm{C}$, respectively, in an illumination set to $3000 \mathrm{Lx}$. Subsequently, we obtained leaves after $12 \mathrm{~h}, 36 \mathrm{~h}$ and $60 \mathrm{~h}$ of low-temperature treatment for RNA- 
seq and related indexes

\section{Relative conductivity (REC)}

The relative conductivity was measured by referring to the method of $\mathrm{Xu}$ [28]. The specific procedure was to take a $2 \times 4 \mathrm{~cm}$ leaf from the middle of the first fully expanded leaf of each seedling. Then, mixed the leaves, cut the leaves into $1 \mathrm{~cm}$ segments, divided them into 3 portions, transferred them into $10 \mathrm{~mL}$ EP tubes, and finally filled the tubes with distilled water. After soaking the blades in water for $3 \mathrm{~h}$, the EC1 was determined by the conductivity meter; then, boiled the samples in a water bath for $10 \mathrm{~min}$, followed by cooling them at room temperature and measured EC 2 by a conductivity meter.

Calculation formula of relative conductivity: REC=EC1/EC $2 \times 100 \%$.

\section{Determination of chlorophyll a, b and carotenoid contents}

For extracting chloroplast pigment, $0.2 \mathrm{~g}$ fresh leaves were homogenated with $95 \%$ ethanol and centrifuged at $10,000 \mathrm{~g}$ for $10 \mathrm{~min}$ at room temperature. The extracted chloroplast pigment was poured into a colorimetric cup ( $1 \mathrm{~cm}$ with diameter). The absorbance was measured of $663 \mathrm{~nm}, 646$ nm and $470 \mathrm{~nm} 95 \%$ ethanol as blank, using a UV-visible spectrophotometer (model UV-1800). The absorbance was measured at wavelengths of $663 \mathrm{~nm}, 646 \mathrm{~nm}$ and $470 \mathrm{~nm}$ with $95 \%$ ethanol as blank [29]. The calculation formula was as follows:

The concentration of chlorophyll a =12.21 $\times$ OD663-2.81 $\times$ OD646

The concentration of chlorophyll $b=20.13 \times$ OD646-5.03 $\times$ OD663

Concentration of carotenoids $=(1000 \mathrm{~A} 470-3.27 \mathrm{Cha}-104 \mathrm{Chb}) / 229$

\section{Determination of ROS content and Antioxidant enzyme activity}

The test kit purchased from Suzhou Keming Biotechnology Co., LTD, was used to determine Proline (Pro), Superoxide dismutase (SOD), and Peroxidase (POD), Catalase (CAT) and Reactive oxide species (ROS). Among them, the determination instrument is UV-visible visible spectrophotometer.

\section{RNA extraction and detection}

Beijing Novogene Technology Co., LTD completed RNA extraction and detection. 


\section{cDNA library construction and sequencing}

The Beijing Novogene Technology Co., LTD constructed the cDNA library and sequenced it by adopting the Oligo(dT) magnetic beads enriched mRNA with polyA tail procedures. Briefly, mRNA was randomly fragmented by divalent cation in NEB Fragmentation Buffer. The first strand of cDNA was prepared using random oligonucleotide as a primer, and the second strand was synthesized using DNA polymerase I. The ends of purified double-stranded cDNA were repaired by adding a tail and sequencing connector and screened 250-300 bp cDNA for PCR amplification. The PCR product was purified again to obtain the final library, and after qualifying the library, finally used Illumina Hiseq ${ }^{\mathrm{TM}} 4000$ sequencing platform for sequencing.

\section{Data filtering and splicing assembly}

High-quality sequence data was obtained by filtering the raw reads to a small number of reads containing sequencing adaptors, and which did not show the base information were considered lowsequencing reads. Through statistical Q20 (Phred = -10log10 (e)), Q30 (Phred = -10log10 (e)), GC content and sequencing error (not more than 6\%), and other indicators of sequencing quality control.

Trinity software [30] was used to obtain clean reads of transcripts for later analysis. The Tgicl software was used to obtain Unigenes by homologous clustering for later analysis. Sequence the splicing transcript according to its length from long to short, and add the length of the transcript to the length of the splicing transcript that is not less than $50 \% / 90 \%$ of the total length, namely N50/N90, to measure the continuity of De Novo assembly, and its numerical value can be used to evaluate the quality of the assembly effect.

\section{Unigenes function comment}

It was used Blast [31] to get Unigenes and carried out functional annotation in the following 7 databases: NR, NT, GO, KOG, KO (KEGG), Swiss-Prot, and FPKM.

\section{Screening and functional annotation analysis of differentially expressed genes}

RSEM method [32] was used for the quantitative analysis of gene expression. The clean data of all sample was compared on the reference sequence obtained by Trinity splicing, and the read count to a gene was obtained by the Bowtie 2 method. The read count was converted into an FPKM (expected number of Fragments Per Kilobase of transcript sequence Per Millions base set 
sequenced), and the gene expression level was evaluated by using the FPKM value [28, 33] (FPKM $>0.3$ regarded as gene expression).

According to statistical analysis, the level of gene expression screening of differentially expressed genes between different samples, DEG-Seq software [34] to the original read count for standardization, through the negative binomial distribution hypothesis test probability statistical model (P-value) calculation, and finally $(\mathrm{BH})$ adjustment for multiple hypothesis testing, by FDR value (False Discovery Rate, namely padj), $\mid \log _{2}$ (FoldChange) $\mid>1$ and padj $<0.05$ was considered as the standard for differential gene screening.

GO biological enrichment analysis was performed on the differential gene set by the GO-seq method [35], and KEGG metabolism and signal transduction pathway enrichment analysis was performed on the differential gene set by KOBAS method [36]. Padj $<0.05$ was used as the threshold of significant enrichment in both of the above two analyses.

\section{Real-time PCR validated the transcriptome results}

In order to verify the accuracy of transcriptome sequencing results, six genes were randomly selected for real-time PCR detection. Primer5.0 was used to design differential gene sequence primers (Tables. S9) with Actin as the internal reference gene, with $2^{-\Delta \Delta} \mathrm{CT}$ method to calculate relative gene expression, three biological replicates and three technical replicates were set for each sample. $10 \mu \mathrm{L}$ PCR amplification was $1 \mu \mathrm{L}$ cDNA， $5 \mu \mathrm{L}$ qPCR Super mix, $0.4 \mu \mathrm{L}$ Forward/Reverse Primer, $3.2 \mu \mathrm{L}$ Nuclease-free Water. The reaction conditions were set as pre-denaturation $95^{\circ} \mathrm{C}, 3$ min; Denaturation $95^{\circ} \mathrm{C}, 10 \mathrm{~s}$; Annealing at $60^{\circ} \mathrm{C}, 30 \mathrm{~s}$; Extension $72^{\circ} \mathrm{C}, 30 \mathrm{~s}, 40$ cycles.

\section{Figures:}

Fig. 1 I, II and III show growth conditions of Helictotrichon Virescens at low temperature for 12h, 36h and $60 \mathrm{~h}$, respectively. Treatment was $0^{\circ} \mathrm{C}$ and $\mathrm{CK}$ was $25^{\circ} \mathrm{C}$. BLYM: Helictotrichon virescens

Fig. 2 Physiological responses of cold tolerance adaptability of Helictotrichon Virescens. BLYM: Helictotrichon virescens

Fig. 3 A Species distribution. B Sequence similarity distribution

Fig. 4 a: FPKM interval. Bar: The abscissa is the number distribution of genes in each FPKM interval. Different colors represent different expression intervals. In this figure, the overall 
distribution of FPKM of each sample can be compared and viewed. b: Heat map of the correlation coefficient between samples. Note: The abscissa is $\log 10$ of sample $1(\mathrm{FPKM}+1)$, the ordinate is $\log 10$ of sample $2(\mathrm{FPKM}+1)$, and R2 is the square of Pearson's correlation coefficient. c、 d and e: Volcano map of differential genes. Note: In the figure, the abscissa is $\log 2$ Fold Change value, and the ordinate is $-\log 10$ padj or $-\log 10$ p-value. The dashed blue line represents the threshold line of differential gene screening criteria. f: Venn diagram of different genes after $12 \mathrm{~h}, 36 \mathrm{~h}$ and $60 \mathrm{~h}$ cryogenic treatment.

Fig. 5 (a) Heat maps of differentially expressed genes in related biological processes. (b) Heat map of differentially expressed genes in the photosynthetic pathway. (c) Heat map of differentially expressed genes in the photosynthesis-antenna protein pathway. (d) Heat maps of differentially expressed genes in the plant-circadian pathway. BLYM: Helictotrichon virescens.

Fig. 6 Distribution of differentially expressed transcription factors in different gene families

Fig. 7 Fold change distribution of transcription factor genes Note: a, b and c are the expression multiples of transcription factor genes after $12 \mathrm{~h}, 36 \mathrm{~h}$ and $60 \mathrm{~h}$ low temperature treatment, respectively.

Fig. 8 RNA-seq results verified by RT-PCR

Fig9 Photographs of Helictotrichon virescens

\section{Tables:}

Table 1 Statistics of gene annotation

Table 2 Transcription factors with large difference multiple under low temperature stress (after 12h treatment)

Table 3 Transcription factors with large difference multiple under low temperature stress (after $36 \mathrm{~h}$ treatment)

Table 4 Transcription factors with large difference multiple under low temperature stress (after 60h treatment)

\section{Acknowledgements}

All authors are grateful to the laboratory members for help, advice and discussion. All authors are grateful to the editors and referees for their valuable comments to improve our manuscript.

\section{Authors' contributions}

RH, KC, RZ, and DY analyzed transcriptome analysis and wrote manuscript. TY and JZ determined 
physiological indexes. MY, XL and TM helped in data collection and statistical analysis. MZ, XL and MZI revised the manuscript. MC provided funds and approved the manuscript. All authors read and approved its content.

\section{Funding}

This study was supported by the Science and Technology Project of Sichuan Province (2020YJ0466), the Forage Innovation Team of Sichuan Province, and the Public Relations Project of Forage Breeding of Sichuan Province. Funding for transcriptome sequencing was provided by the Science and Technology Project of Sichuan Province (2020YJ0466), the physiology experiment was funded by the Forage Innovation Team of Sichuan Province, and the Public Relations Project of Forage Breeding of Sichuan Province.

\section{Availability of data and materials}

The datasets supporting the conclusions of this article are included within the article and its additional files. The original data of RNA sequences will be uploaded to the NCBI database and relevant login information will be provided.

\section{Declarations}

\section{Ethics approval and consent to participate}

The experimental materials for this study were cultivated by Sichuan Grass Industry Technology Research and Promotion Center, Grassland Station of Ganzi Prefecture, Sichuan Province and Sichuan Jinzong Liaoyuan Seed Industry Technology Co. Ltd and without any controversy, it comply with relevant institutional, national, and international guidelines and legislation.

\section{Consent for publication}

Not applicable.

\section{Competing interests}

The authors declare that they have no competing interests.

\section{Author details}


${ }^{2}$ Maize Research Institute, Sichuan Agricultural University, Chengdu 611130, China.

Utilization of Characteristic Horticultural Biological Resources, Chengdu Normal University, Chengdu, 611130, China.

${ }^{5}$ Sichuan Agricultural Technology Extension Station, Chengdu, 610041, China.

$592{ }^{6}$ Institute of Agricultural Information and Rural Economy, Sichuan Academy of Agricultural 593 Sciences, Chengdu, 610066, China.

\section{References}

595 1. Wisniewski M, Nassuth A, Teulières C, Marque C, Rowland J, Cao PB, et al. Genomics of cold hardiness in woody plants. Critical Reviews in Plant Sciences. 2014;33(2-3):92-124.

2. Powles SB. Photoinhibition of photosynthesis induced by visible light. Annual Review of Plant

599 3. Fm A, Hka B. Direct inhibition of photosynthesis by $\mathrm{Cd}$ dominates over inhibition caused by 600 micronutrient deficiency in the $\mathrm{Cd} / \mathrm{Zn}$ hyperaccumulator Arabidopsis halleri. Plant Physiology

4. Galka P, Santabarbara S, Khuong TT, Degand H, Morsomme P, Jennings RC, et al. Functional 603

5. N, Sui. Photoinhibition of Suaeda salsa to chilling stress is related to energy dissipation and

6. Baker NR. A possible role for photosystem II in environmental perturbations of photosynthesis.

7. Calzadilla PI, Signorelli S, Escaray FJ, Menéndez AB, Monza J, Ruiz OA, et al. Photosynthetic responses mediate the adaptation of two Lotus japonicus ecotypes to low temperature. Plant Science. 2016;250:59-68.

8. Seo PJ, Mas P. Stressing the role of the plant circadian clock. Trends Plant Sci. 2015;20(4):230237.

9. Osterlund MT, Hardtke CS, Wei N, De Ng XW. Targeted destabilization of HY5 during lightregulated development of Arabidopsis. Nature. 2000;405(6785):462-466.

10. Tepperman JM, Zhu T, Chang HS, Wang X, Quail PH. Multiple transcription-factor genes are early targets of phytochrome A signaling. Proceedings of the National Academy of Sciences. 2001;98(16):9437-9442.

11. Wang F, Zhang L, Chen X, Wu X, Xiang X, Zhou J, et al. SIHY5 integrates temperature, light and 
hormone signaling to balance plant growth and cold tolerance. Plant physiology. 2019;179(2):749-760.

12. Catalá R, Medina J, Salinas J. Integration of low temperature and light signaling during cold acclimation response in Arabidopsis. Proceedings of the National Academy of Sciences of the United States of America. 2011;108(39):16475-16480.

13. Srivastava D, Shamim M, Kumar M, Mishra A, Maurya R, Sharma D, et al. Role of circadian rhythm in plant system: An update from development to stress response. Environmental and Experimental Botany. 2019;162:256-271.

14. Fowler SG, Cook D, Thomashow MF. Low temperature induction of Arabidopsis CBF1, 2, and 3 is gated by the circadian clock. Plant physiology. 2005;137(3):961-968.

15. Chinnusamy V, Zhu JK, Sunkar R. Gene regulation during cold stress acclimation in plants. Meth Mol Biol. 2010;639:39-55.

16. Liu B, Zhou H, Cao S, Xia YP, Arora R. Comparative Physiology of Natural Deacclimation in Ten Azalea Cultivars. HortScience: a publication of the American Society for Horticultural Science. 2017;52(10):1451-1457.

17. Atkin OK, Evans JR, Ball MC, Lambers H, Pons TL. Leaf respiration of snow gum in the light and dark. Interactions between temperature and irradiance. Plant physiology. 2000;122(3):915-923.

18. Kurusu T, Kuchitsu K. Autophagy, programmed cell death and reactive oxygen species in sexual reproduction in plants. Journal of plant research. 2017;130(3):491-499.

19. Avin-Wittenberg T. Autophagy and its role in plant abiotic stress management. Plant, cell \& environment. 2019;42(3):1045-1053.

20. Suttangkakul A, Li FQ, Chung T, Vierstra RD. The ATG1/ATG13 protein kinase complex is both a regulator and a target of autophagic recycling in Arabidopsis. The Plant Cell. 2011; 23(10):37613779.

21. Belda-Palazón B, Adamo M, Valerio C, Ferreira LJ, Confraria A, Reis-Barata D, at al. A dual function of SnRK2 kinases in the regulation of SnRK1 and plant growth. Nature Plants. 2020;6:1345-1353.

22. Xin Z, Li PH. Alteration of Gene Expression Associated with Abscisic Acid-Induced Chilling Tolerance in Maize Suspension-Cultured Cells. Plant physiology. 1993;101(1):277-284.

23. Ramos A, Pérez-Solís E, Ibáñez C, Casado R, Collada C, Gómez L, at al. Winter disruption of the circadian clock in chestnut. Proceedings of the National Academy of Sciences of the United States of America. 2005;102(19):7037-7042.

24. Gangappa SN, Botto JF. The Multifaceted Roles of HY5 in Plant Growth and Development. Molecular Plant. 2016;9(10):1353-1365.

25. Tweneboah S, Oh SK. Biological roles of NAC transcription factors in the regulation of biotic and abiotic stress responses in solanaceous crops. Journal of Plant Biotechnology. 2017; 44(1):111.

26. Riechmann J, Heard J, Martin G, Reuber L, Jiang C, Keddie J, at al. Arabidopsis Transcription Factors: Genome-Wide Comparative Analysis Among Eukaryotes. Science. 2000;290(5499):2105-2110.

27. Chen JB, Zhang FR, Huang DF, Zhang LD, Zhang YD. Transcriptome Analysis of Transcription Factors in Two Melon(Cucumis melo L.) Cultivars under Salt Stress. Plant Physiology Journal. 2014;50(2):150-158.

28. Xu J, Yang J, Xu Z, Zhao D, Hu X. Exogenous spermine-induced expression of SISPMS gene 
improves salinity-alkalinity stress tolerance by regulating the antioxidant enzyme system and ion homeostasis in tomato. Plant Physiology and Biochemistry. 2020;157(1):79-92.

29. Lichtenthaler HK. Chlorophylls and carotenoids: Pigments of photosynthetic biomembranes. Methods in enzymology. 1987;148C:350-382.

30. Grabherr MG, Haas BJ, Yassour M, Levin JZ, Thompson DA, Amit I, et al. Full-length transcriptome assembly from RNA-Seq data without a reference genome. Nature Biotechnology. 2011;29(7):644-652.

31. Altschul SF. Basic local alignment search tool (BLAST). Journal of Molecular Biology. 2012;215(3):403-410.

32. Li B, Dewey CN. RSEM: accurate transcript quantification from RNA-Seq data with or without a reference genome. BMC bioinformatics. 2011; 12:323.

33. Trapnell C, Williams BA, Pertea G, Mortazavi A, Kwan G, Baren M, at al. Transcript assembly and quantification by RNA-Seq reveals unannotated transcripts and isoform switching during cell differentiation. Nature Biotechnology. 2010;28(5):511-515.

34. Love MI, Huber W, Anders S. Moderated estimation of fold change and dispersion for RNA-seq data with DESeq2. Genome Biology. 2014;15(12):550.

35. Young MD, Wakefield MJ, Smyth GK, Oshlack A. Gene ontology analysis for RNA-seq: accounting for selection bias. Genome Biology. 2010;11(2):R14.

36. Minoru K, Michihiro A, Susumu G, Masahiro H, Mika H, Masumi I, at al. KEGG for linking genomes to life and the environment. Nucleic Acids Research. 2008;36(Database issue):480484. 
Figures

\section{Figure 1}

I, II and III show growth conditions of Helictotrichon Virescens at low temperature for $12 \mathrm{~h}, 36 \mathrm{~h}$ and $60 \mathrm{~h}$, respectively. Treatment was 0 . and CK was 25.. BLYM: Helictotrichon virescens
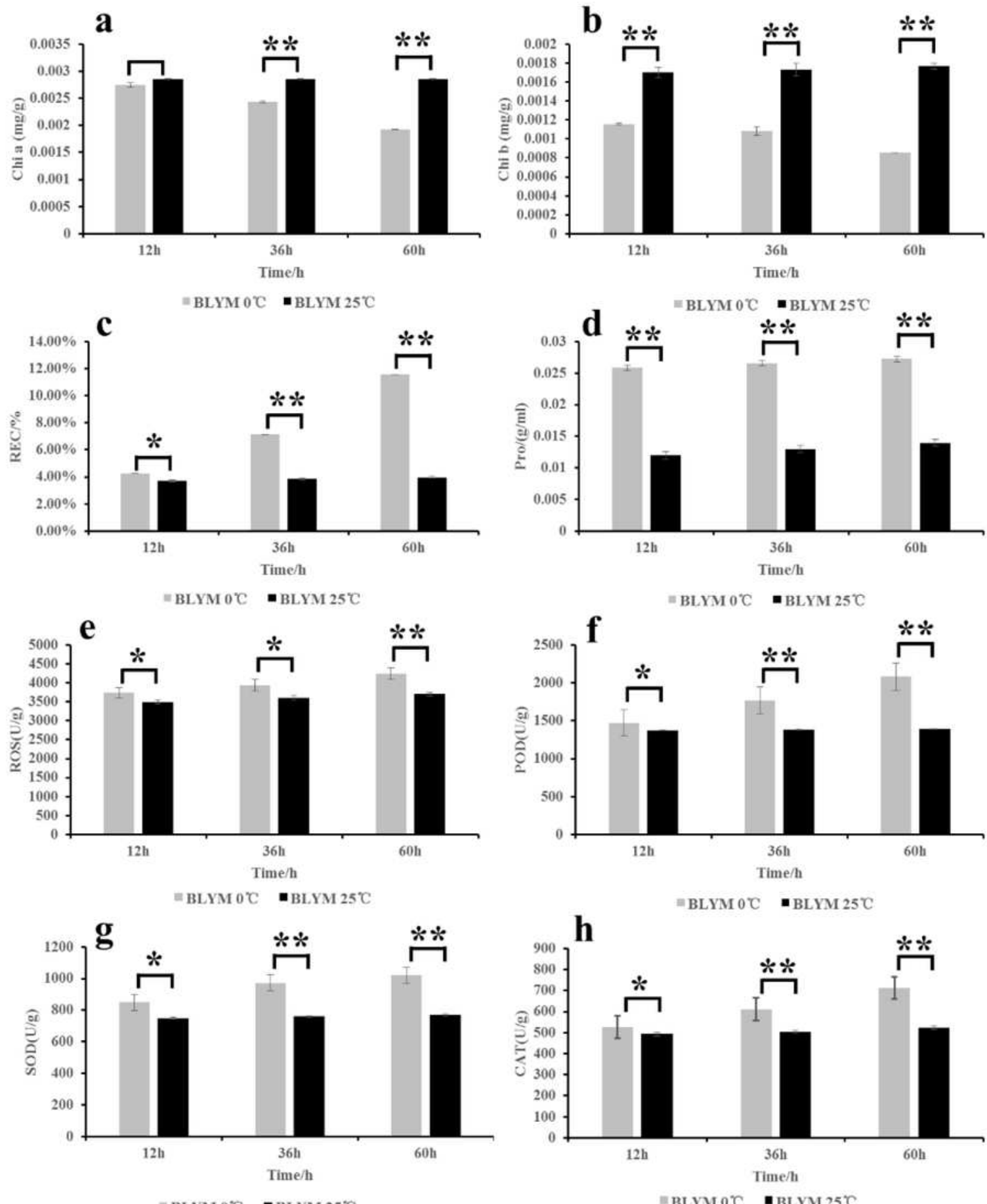


\section{Figure 2}

Physiological responses of cold tolerance adaptability of Helictotrichon Virescens. BLYM: Helictotrichon virescens

a

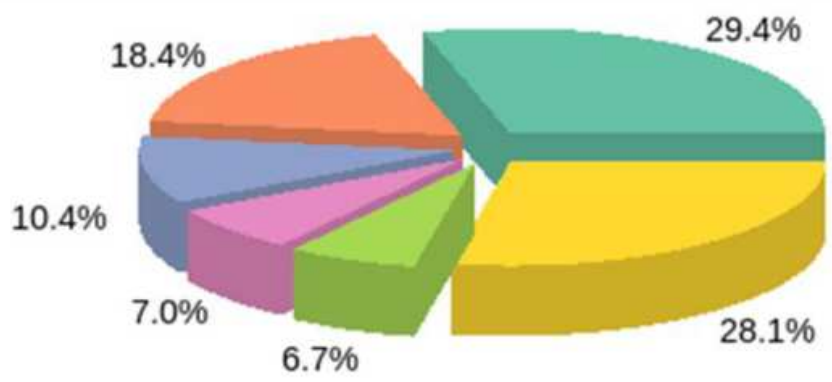

$\square$ Aegilops tauschii ....
$\square$ Brachypodium distachyon
$\square$ Hordeum vulgare ...
$\square$ Triticum aestivum
$\square$ Triticum urartu
$\square$ other

b

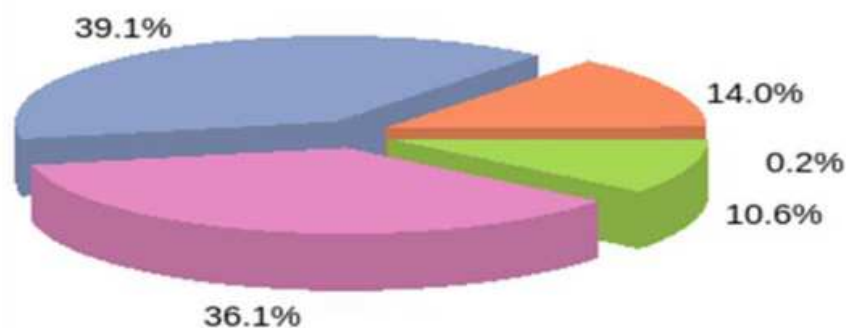

$18 \% \sim 40 \%$
$\square \quad 40 \% \sim 60 \%$
$\square \quad 60 \%-80 \%$

ㅁ 80\% 95\%

ㅁ $95 \% \sim 100 \%$

\section{Figure 3}

A Species distribution. B Sequence similarity distribution 
Fig 4
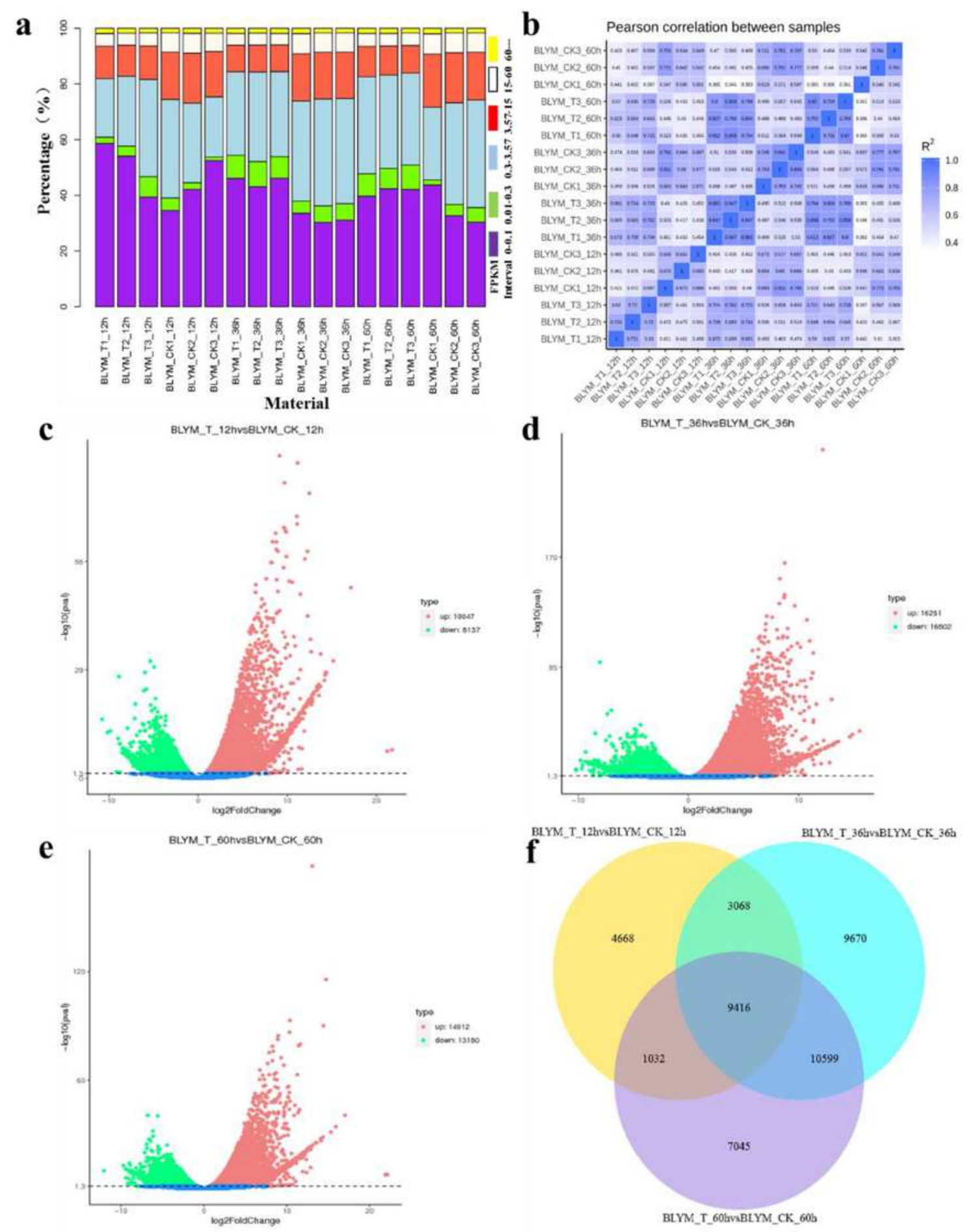

\section{Figure 4}

a: FPKM interval. Bar: The abscissa is the number distribution of genes in each FPKM interval. Different colors represent different expression intervals. In this figure, the overall distribution of FPKM of each sample can be compared and viewed. b: Heat map of the correlation coefficient between samples. Note: The abscissa is $\log 10$ of sample $1(\mathrm{FPKM}+1)$, the ordinate is $\log 10$ of sample $2(\mathrm{FPKM}+1)$, and $\mathrm{R} 2$ is the square of Pearson's correlation coefficient. c.d and e: Volcano map of differential genes. Note: In the 
figure, the abscissa is Log2 Fold Change value, and the ordinate is -Log10 padj or -Log10 p-value. The dashed blue line represents the threshold line of differential gene screening criteria. $f$ : Venn diagram of different genes after $12 \mathrm{~h}, 36 \mathrm{~h}$ and $60 \mathrm{~h}$ cryogenic treatment.



\section{Figure 5}

(a) Heat maps of differentially expressed genes in related biological processes. (b) Heat map of differentially expressed genes in the photosynthetic pathway. (c) Heat map of differentially expressed genes in the photosynthesis-antenna protein pathway. (d) Heat maps of differentially expressed genes in the plant-circadian pathway. BLYM:Helictotrichon virescens. 


\begin{tabular}{|c|c|c|}
\hline -Alfin-like & $=A P 2 / E R F-A P 2$ & "AP2/ERF-ERF \\
\hline AP2/ERF-RAV & -ARID & -AUX/AA \\
\hline - B3 & - B3-ARF & - BBR-BPC \\
\hline - BESI & - bHLH & $=b Z I P$ \\
\hline "C2C2-CO-like & - C2C2-Dof & $=\mathrm{C}_{2} \mathrm{C}_{2}$-GATA \\
\hline$=\mathrm{C} 2 \mathrm{C} 2 \mathrm{LSD}$ & - C2C2-YABBY & $-\mathrm{C} 2 \mathrm{H} 2$ \\
\hline - $\mathrm{C} 3 \mathrm{H}$ & - CAMTA & - Coactirator p15 \\
\hline - CPP & - $\operatorname{CSD}$ & - DBB \\
\hline =DBP & - DDT & E2F-DP \\
\hline$=z$ - HD & $=$ HRT & " HSE \\
\hline -IWSI & - Jumonji & -LIM \\
\hline$-\mathrm{LOB}$ & - LUG & - MADSMIKC \\
\hline -MADSM-type & $\cdot \mathrm{MBF} 1$ & " ME D6 \\
\hline MED7 & $=$ mTERF & "MYB-rebted \\
\hline$\because \mathrm{NAC}$ & - NF-YC & - OFP \\
\hline - PHD & - PLATZ & - Pseado ARR-B \\
\hline "RB & -Redl-like & "RWP-RK \\
\hline SIFa-like & $=\mathrm{SBP}$ & SEI \\
\hline$=$ SNF 2 & - ma-clus & $=\mathrm{EIL}$ \\
\hline "FAR1 & - GARP-ARR-B & "GARP-G2-like \\
\hline - GeBP & - GNAT & - GRAS \\
\hline . GRF & - HB-BELL & -HB-HD-ZIP \\
\hline "HB-KNOX & - HB-other & " HB-PHD \\
\hline HB-WOX & - HMIG & " SOHl \\
\hline - SRS & - SWVISNF-B.AF60b & - STVUSNF-STVI3 \\
\hline "TAZ & - TCP & - Tify \\
\hline - TR.AF & - Trihelix & $=\mathrm{TUB}$ \\
\hline ULT & $=\mathrm{VOZ}$ & = WRKY \\
\hline
\end{tabular}

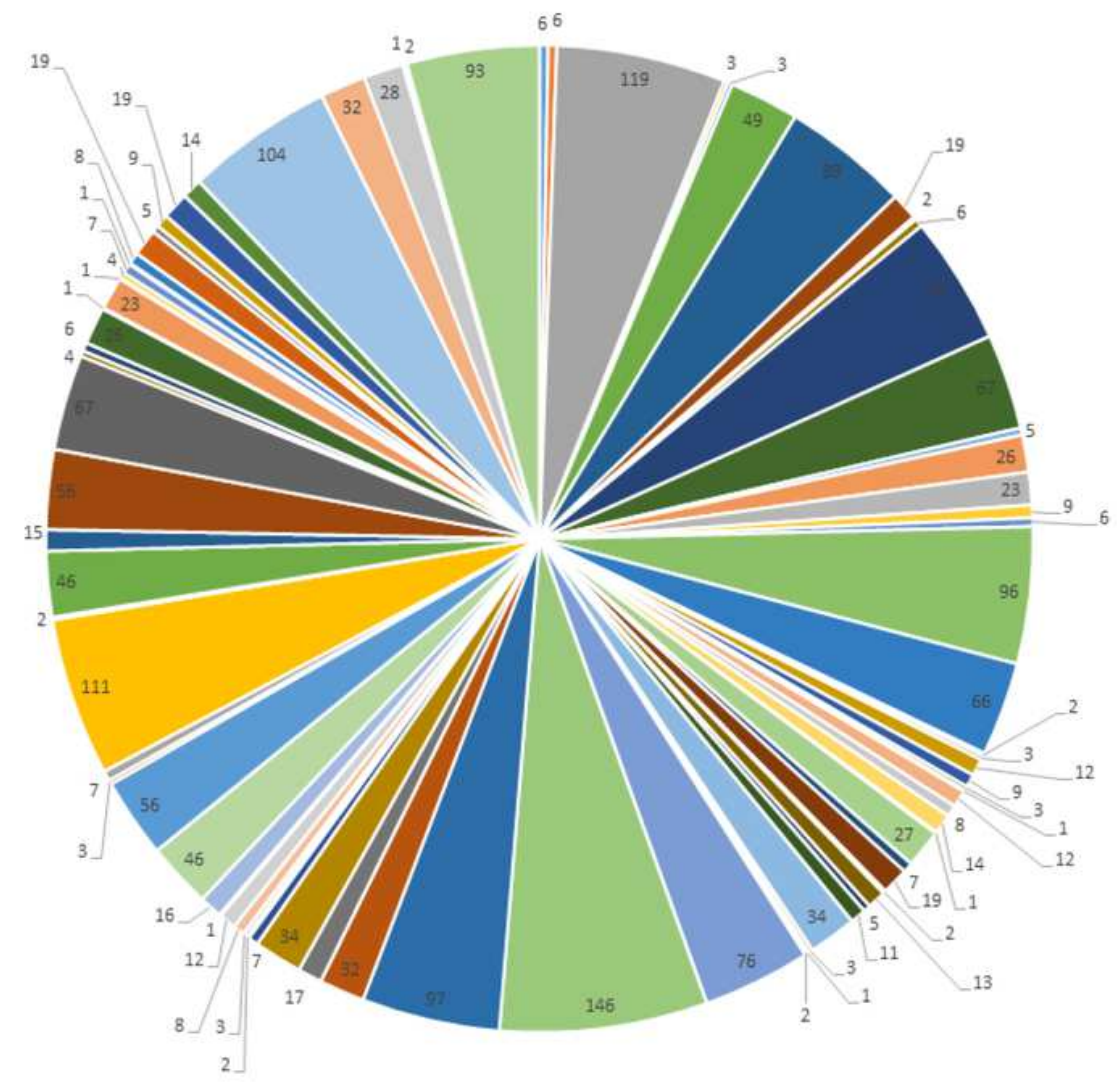

Figure 6

Distribution of differentially expressed transcription factors in different gene families 
a

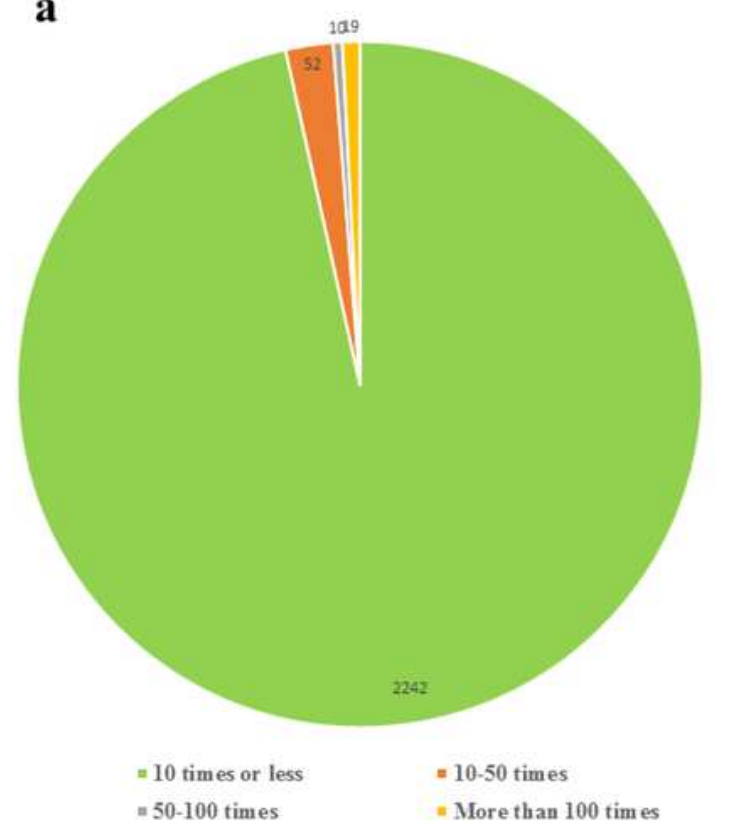

b

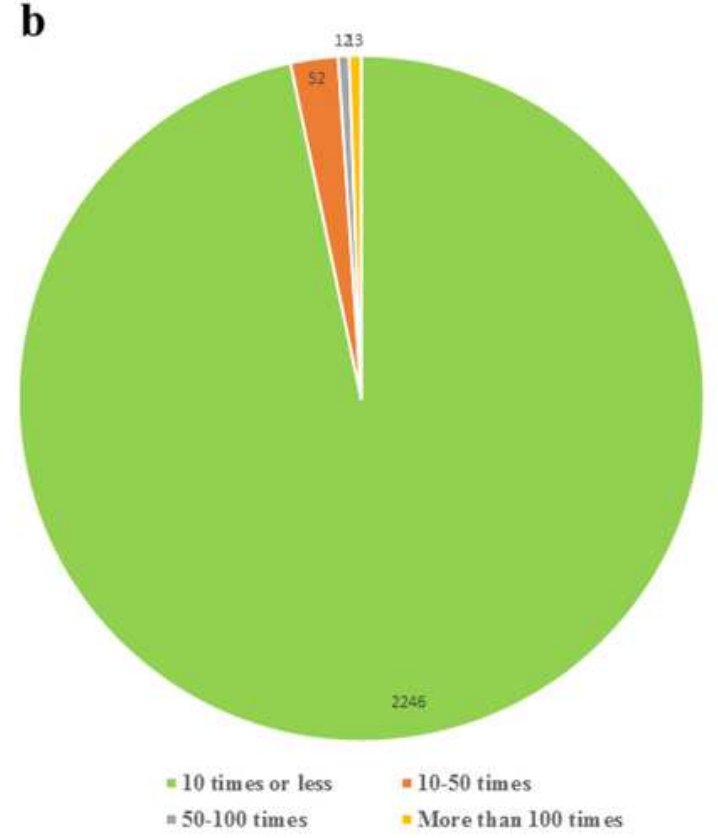

c

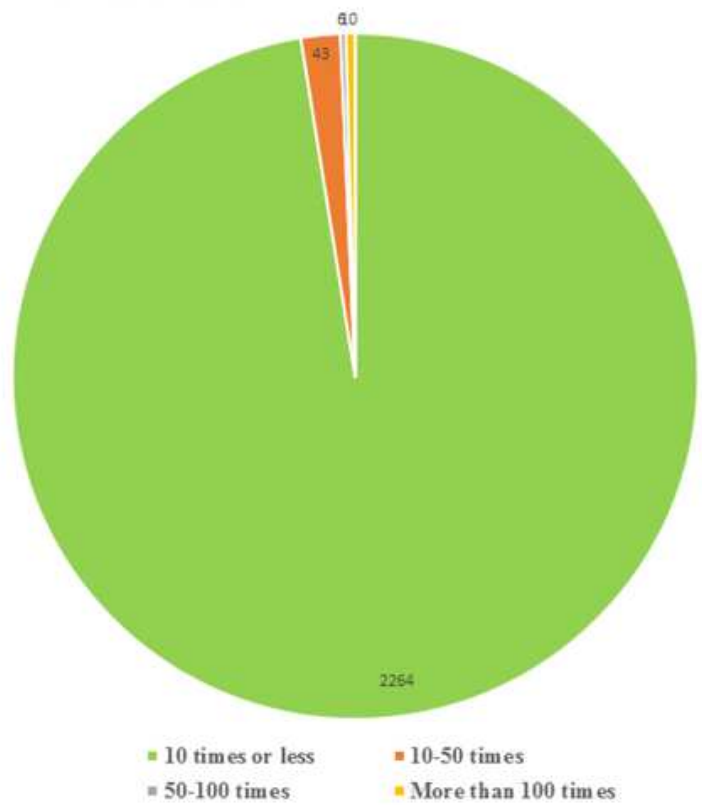

Note: $\mathrm{a}, \mathrm{b}$ and $\mathrm{c}$ are the expression multiples of transcription factor genes after $12 \mathrm{~h}, 36 \mathrm{~h}$ and $60 \mathrm{~h}$ low temperature treatment, respectively.

\section{Figure 7}

Fold change distribution of transcription factor genes Note: $a, b$ and $c$ are the expression multiples of transcription factor genes after $12 \mathrm{~h}, 36 \mathrm{~h}$ and $60 \mathrm{~h}$ low temperature treatment, respectively. 

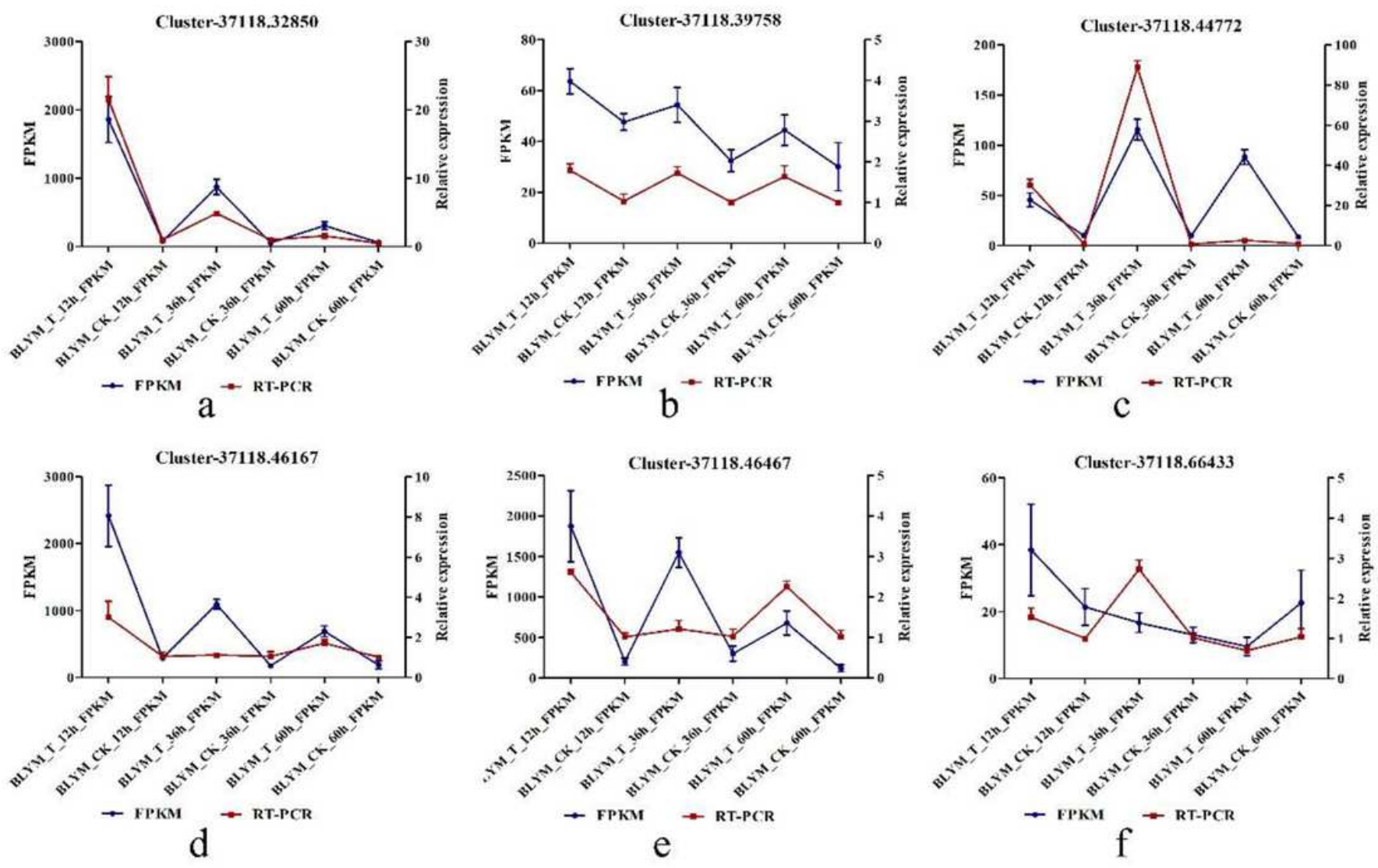

Figure 8

RNA-seq results verified by RT-PCR

R

Figure 9

Photographs of Helictotrichon virescens 


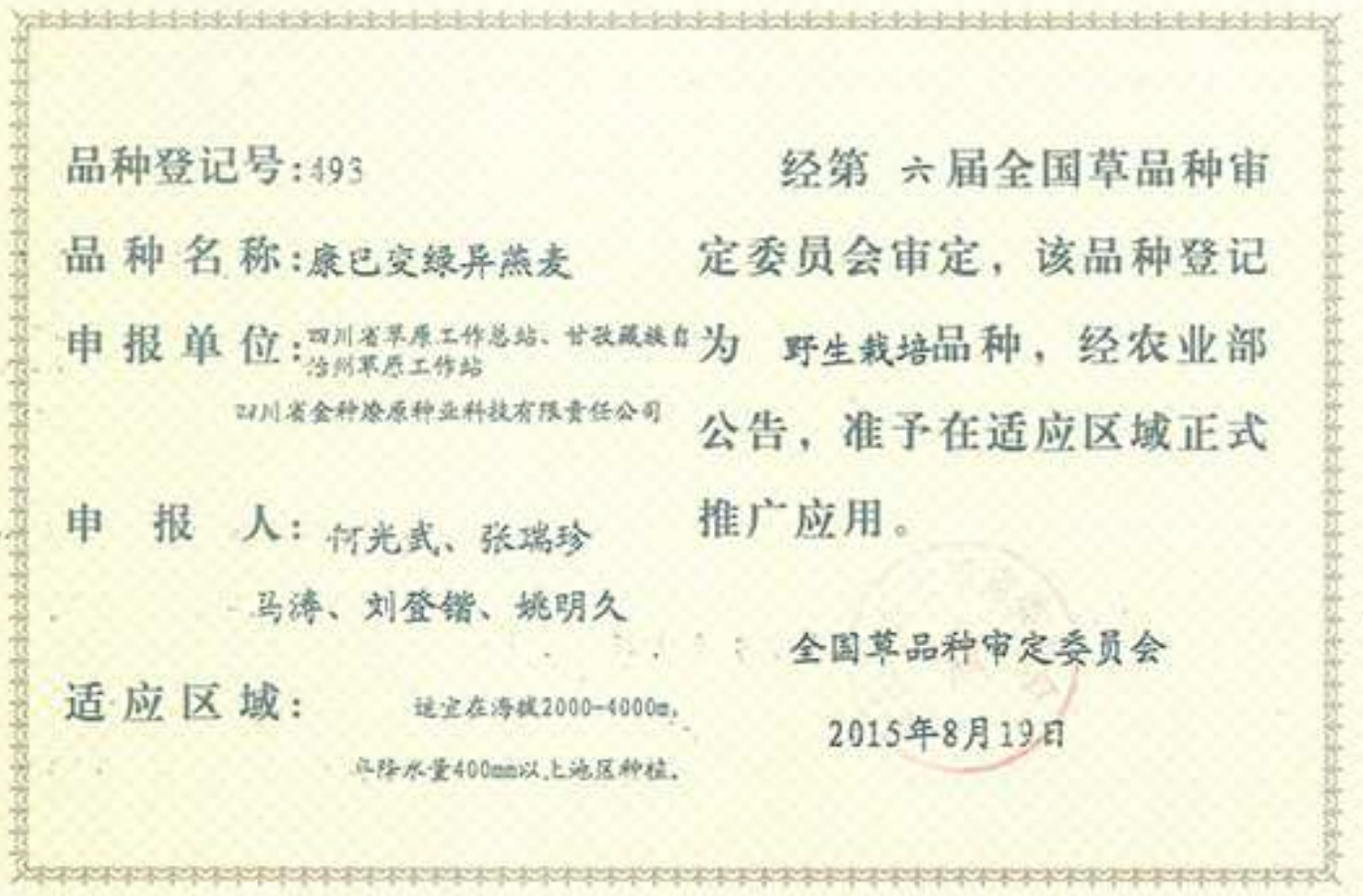

Fig10 Variety certification certificate

\section{Figure 10}

See image above for figure legend

\section{Supplementary Files}

This is a list of supplementary files associated with this preprint. Click to download.

- Additionalfile.pdf

- Additionalfile2.pdf 